\title{
Nuchal cord: from dread towards confident management
}

\author{
Shilpa S. K.*, Sadia Moin, Naima Fatima
}

Department of Obstetrics and Gynecology, Shri Venkata Sai Medical College, Mahabubnagar, Telangana, India

Received: 03 April 2020

Accepted: 13 April 2020

\section{*Correspondence:}

Dr. Shilpa S. K.,

E-mail: shilpaindia1mbnr@gmail.com

Copyright: (C) the author(s), publisher and licensee Medip Academy. This is an open-access article distributed under the terms of the Creative Commons Attribution Non-Commercial License, which permits unrestricted non-commercial use, distribution, and reproduction in any medium, provided the original work is properly cited.

\section{ABSTRACT}

Background: This study was aimed at observing the outcomes of pregnancies with sonographically detected nuchal cord or cord around the neck at term. Early studies on nuchal cord showed many maternal and neonatal complications. But several recent studies have suggested that maternal and neonatal complications do not increase with nuchal cord at delivery. This ambiguity increases anxiety in treating obstetricians and relatives of pregnant women, thus leading to unnecessary caesarean sections. This study is intended to observe the maternal and neonatal outcomes of 300 pregnant women with sonographically detected nuchal cord at term.

Methods: Prospective observational study where 300 term pregnant women with sonographically detected nuchal cord were observed through delivery at Shri Venkata Sai Medical College, Mahabubnagar, Telangana, during October 2016 to April 2018.

Results: In this study $80.6 \%$ women had normal vaginal delivery, $8.3 \%$ had LSCS, $11 \%$ had instrumental deliveries. $54 \%$ had loose nuchal cord, $46 \%$ had tight loop of cord.60\% had normal CTG, $8 \%$ had variable deceleration, $2 \%$ late deceleration. Neonatal morbidity was $9.6 \%$ and zero neonatal mortality.

Conclusions: The study concluded that the presence of nuchal cord does not adversely affect the mother and the neonate. Presence of nuchal cord per se is not an indication for LSCS. Effect of nuchal cord on neonate is only transient. These women can be allowed for vaginal delivery with routine labour room protocols. Routine sonographycal detection of nuchal cord is not required and if it is reported, it should not dictate obstetric management.

Keywords: Delivery, Neonatal mortality, Nuchal cord

\section{INTRODUCTION}

Umbilical cord is the life line connecting mother and baby. Nuchal cord is defined as an umbilical cord that passes $360^{\circ}$ around the neck. ${ }^{1}$ Historically nuchal cord is considered dangerous for both mother and baby since the time of Hippocrates. Early researches showed that foetuses with nuchal cord at delivery had increased incidence of foetal heart rate decelerations during labour, increased incidence of acidaemia, higher incidence of neonatal resuscitation, NICU admissions, increased need for operative vaginal delivery. ${ }^{2-4}$ Many recent studies have suggested that perinatal and maternal complications do not increase with nuchal cord at delivery. ${ }^{5-8}$ This ambiguity increases anxiety in treating obstetricians and relatives of pregnant women, thus leading to unnecessary caesarean sections.

This prospective observational study is intended to observe the maternal and neonatal outcomes of 300 pregnant women with sonographically detected nuchal cord at term.

Nuchal cords are not uncommon, with prevalence rates ranging between $6 \%$ to $37 \% .^{9}$ The prevalence increases with the duration of pregnancy, from $5.8 \%$ at 20 weeks gestation up to $29 \%$ at 42 weeks. ${ }^{4}$ Nuchal cords can be single or multiple loops, and loose or tightly wrapped around the neck. A nuchal cord is considered to be loose when it could be easily uncoiled before delivery of the 
foetal trunk. When it needed to be clamped and cut before delivery of the trunk, the nuchal cord was considered tight.

Aim and objective is to study maternal and neonatal complications in pregnant women with sonographically detected nuchal cord.

\section{METHODS}

This is a prospective observational study conducted in department of obstetrics and gynecology, Shri Venkata Sai Medical College, Mahabubnagar, Telangana from October 2016 to April 2018. Study included 300 term pregnant women with sonographically detected nuchal cord and were admitted in early labour with following inclusion and exclusion criteria.

\section{Inclusion criteria}

- Term pregnancy, singleton pregnancy, cephalic presentation, spontaneous onset of labour, nuchal cord at delivery.

\section{Exclusion criteria}

- Pregnancy complicated with pre-eclampsia, eclampsia, any medical disorders like diabetes mellitus, cardiac disease, severe anaemia, IUGR, oligohydramnios, prelabour rupture of membranes, preterm, multiple pregnancy, previous LSCS, absent nuchal cord at delivery.

Maternal outcome is analysed in terms of mode of delivery as normal vaginal delivery, caesarean section or instrumental delivery. Neonatal outcomes are analysed by means of Apgar score of the neonate at 1 and 5 minutes, NICU admission, birth asphyxia, meconium aspiration syndrome.

\section{RESULTS}

In this study 300 term pregnant women with sonographically detected nuchal cord were included. In this study $47 \%$ were primigravida, $53 \%$ were multigravida (Table 1).

Table 1: Obstetric score.

\begin{tabular}{|ll|}
\hline Obstetric score & Number of cases \\
\hline Primigravida & $140(46 \%)$ \\
\hline Multigravida & $160(54 \%)$ \\
\hline
\end{tabular}

Table 2: Types of nuchal cord.

\begin{tabular}{|ll|}
\hline Types of nuchal cord & Number of cases \\
\hline Loose nuchal cord & $162(54 \%)$ \\
\hline Tight nuchal cord & $138(46 \%)$ \\
\hline
\end{tabular}

Majority of subjects belonged to age group of 20-25 years. 54\% had loose nuchal cord and $46 \%$ had tight loops of nuchal cord at delivery in total 300 pregnant women observed (Table 2). Most commonly observed nuchal cord in this study was single loop of cord which was loose loop (Table 3).

Table 3: Denoting number of loops of nuchal cord which were tight and loose.

\begin{tabular}{|llll|}
\hline $\begin{array}{l}\text { No. of } \\
\text { loops }\end{array}$ & Tight loops & Loose loops & Total \\
\hline 1 & $69(47.9 \%)$ & $75(52.1 \%)$ & $144(48 \%)$ \\
\hline 2 & $57(40.7 \%)$ & $83(59.3 \%)$ & $140(46.6 \%)$ \\
\hline 3 & $12(80 \%)$ & $3(1 \%)$ & $15(5 \%)$ \\
\hline 4 & 0 & 1 & 1 \\
\hline
\end{tabular}

Table 4: Relationship of length of cord and loops of nuchal cord.

\begin{tabular}{|llll|}
\hline No. of loops & $\mathbf{4 0 - 4 5} \mathrm{cm}$ & $\mathbf{4 6 - 6 0} \mathrm{cm}$ & $>\mathbf{6 0} \mathrm{cm}$ \\
\hline 1 & 85 & 59 & 2 \\
\hline 2 & 6 & 59 & 74 \\
\hline 3 & 0 & 2 & 8 \\
\hline 4 & 0 & 0 & 1 \\
\hline
\end{tabular}

Maternal outcome is measured in this study by the mode of delivery. $80.6 \%$ of women with nuchal cord had normal vaginal delivery, instrumental deliveries were $11 \%$ and LSCS were $8.3 \%$ (Table 5).

Table 5: Mode of delivery.

\begin{tabular}{|lll|}
\hline Mode of delivery & $\begin{array}{l}\text { Number of } \\
\text { cases }\end{array}$ & Percentage \\
\hline Normal vaginal delivery & 242 & $80.6 \%$ \\
\hline Instrumental delivery & 33 & $11 \%$ \\
\hline LSCS & 25 & $8.3 \%$ \\
\hline
\end{tabular}

Table 6: Pregnancy outcomes in tight nuchal cord group and loose nuchal cord group.

\begin{tabular}{|lll|}
\hline Events & $\begin{array}{l}\text { Tight nuchal } \\
\text { cord (138) }\end{array}$ & $\begin{array}{l}\text { Loose nuchal } \\
\text { cord (162) }\end{array}$ \\
\hline Vaginal delivery & $92(66.6 \%)$ & $150(92.5 \%)$ \\
\hline LSCS & $23(16.6 \%)$ & $2(1.2 \%)$ \\
\hline Instrumental delivery & $23(16.6 \%)$ & $10(6.1 \%)$ \\
\hline $\begin{array}{l}\text { Meconium stained } \\
\text { liquor }\end{array}$ & $24(17.3 \%)$ & $5(3 \%)$ \\
\hline
\end{tabular}

CTG was normal in $60 \%$ of parturients, other changes in CTG were late deceleration only in $2 \%$ and variable deceleration in $8 \%$ (Table 8 ). Neonatal outcomes were, NICU admissions were required in $5.6 \%$ (17) of newborns. Apgar score of $<7$ at 5 minutes was seen in only $1.3 \%$ (Table 10). Complications of birth asphyxia was seen in $1 \%$ of neonates, meconium aspiration syndrome was seen in $2.3 \%$. Neonatal mortality was zero. 
Table 7: Pregnancy outcomes in detail.

\begin{tabular}{|llllllll|}
\hline Events & Tight NC & \multicolumn{7}{c|}{ Loose NC } \\
\hline No. of loops & 1 & 2 & 3 & 1 & 2 & 3 & 4 \\
\hline Vaginal delivery (242) & 53 & 38 & 1 & 74 & 74 & 1 & 1 \\
\hline LSCS (25) & 4 & 9 & 10 & 0 & 1 & 1 & \\
\hline Instrumental delivery (33) & 12 & 10 & 1 & 1 & 8 & 1 & 0 \\
\hline Meconium stained liquor & 7 & 10 & 7 & 0 & 4 & 1 & 0 \\
\hline
\end{tabular}

Table 8: CTG changes.

\begin{tabular}{|ll|}
\hline CTG changes & Number of cases \\
\hline Normal CTG & $180(60 \%)$ \\
\hline Early deceleration & $88(30 \%)$ \\
\hline Variable deceleration & $26(8 \%)$ \\
\hline Late deceleration & $6(2 \%)$ \\
\hline
\end{tabular}

Table 9: Neonatal outcomes.

\begin{tabular}{|ll|}
\hline Neonatal outcomes & Number of cases \\
\hline NICU admissions & $17(5.6 \%)$ \\
\hline Baby on mother's side & $283(94.3 \%)$ \\
\hline Birth asphyxia & $3(1 \%)$ \\
\hline Meconium stained liquor & $29(9 \%)$ \\
\hline Meconium aspiration syndrome & $07(2.3 \%)$ \\
\hline
\end{tabular}

Table 10: Apgar Score.

\begin{tabular}{|lll|}
\hline Apgar $<7$ & $\begin{array}{l}\text { Tight nuchal } \\
\text { cord }\end{array}$ & $\begin{array}{l}\text { Loose nuchal } \\
\text { cord }\end{array}$ \\
\hline 1 minute & $42(14 \%)$ & $19(6.3 \%)$ \\
\hline 5 minutes & $4(1.3 \%)$ & $0(0.0 \%)$ \\
\hline
\end{tabular}

Table 11: Neonatal outcomes in relation to tight and loose nuchal cord groups.

\begin{tabular}{|lll|}
\hline Event & $\begin{array}{l}\text { Tight nuchal } \\
\text { cord (138) }\end{array}$ & $\begin{array}{l}\text { Loose nuchal } \\
\text { cord (162) }\end{array}$ \\
\hline NICU admission & $16(5.3 \%)$ & $1(0.3 \%)$ \\
\hline Birth asphyxia & $2(0.6 \%)$ & $1(0.3 \%)$ \\
\hline $\begin{array}{l}\text { Meconium aspiration } \\
\text { syndrome }\end{array}$ & $7(2.3 \%)$ & $0(0.0 \%)$ \\
\hline
\end{tabular}

\section{DISCUSSION}

A total 300 term pregnant women with sonographically detected nuchal cord and who actually had nuchal cord at delivery were included and observed for maternal and neonatal complications.

In this study $47 \%$ were primigravida, $53 \%$ were multigravida (Table 1). This study is comparable to Mastrobattista et al and Schaffer et al with higher incidence of cord around neck among multigravida since an increased intra uterine space in a multigravida allows for easy movements of the fetus, hence increasing the probability of cord around neck. ${ }^{10,11}$

Maximum number of cases with nuchal cord belong to age group 20-25 year (52.33\%) and there is no association of age of pregnant women to the presence of nuchal cord. Pregnancies are more common in this age group. 54\% had loose nuchal cord and $46 \%$ had tight loops of nuchal cord at delivery in total 300 pregnant women with nuchal cord (Table 2).

Present study had $48 \%$ single loop of nuchal cord, $46.6 \%$ double loop nuchal cord, $5 \%$ three loops of nuchal cord and one lady had four loops of nuchal cord (Table 3).

Almost half of this study group (48\%) had single loop of nuchal cord, of which $47.9 \%$ were tight loops and $52.1 \%$ were loose loops. In the double loop group $40.7 \%$ of babies had tight loops and 59.3\% had loose loops of nuchal cord. In the triple loop group 80\% had tight loops and $20 \%$ had loose loops (Table 3). Loose loops of cord were more common than tight loops of nuchal cord, similar results were obtained in study by Shrestha NS and Singh N. ${ }^{12}$

As the length of cord increased the number of loops of nuchal cord also increased. Cord length of $>60 \mathrm{~cm}$ had all types of nuchal cords (Table 4). With long umbilical cord, mobility is increased and more chances of cord getting entangled around the neck. Similar results have been documented by other studies by Kan-Pun-Shui and Eastman, Chatterjee and Gupta. ${ }^{13,14}$

Maternal outcome is measured in this study by the mode of delivery. $80.6 \%$ of women with nuchal cord had normal vaginal delivery, instrumental deliveries were $11 \%$ and LSCS were $8.3 \%$ (Table 5).

On further analysis of data, $92.5 \%$ of loose nuchal cord group and $66.6 \%$ of tight nuchal cord group had normal vaginal delivery (Table 6). In this study nuchal cord per se did not increase operative deliveries. Many of the recent studies like Joshi et al, Mahendra G et al, Karunanidhi S et al, Peregrine et al, Miser et al, Larson et al have shown that presence of nuchal cord does not increase operative deliveries and vaginal deliveries can safely be conducted, normal deliveries are between 70$80 \%$ in these studies. ${ }^{8,9,15-18}$ 
Of the 25 women who had LSCS, 23 (92\%) women had tight loops of nuchal cord and only $2(8 \%)$ women had loose nuchal cord. Instrumental delivery was required in 23 women in tight $\mathrm{NC}$ group and 10 in loose NC group (Table 6). Operative delivery was required when nuchal cord were multiple loops and were tight (Table 7). CTG was normal in $60 \%$ of parturients, other changes in CTG were late deceleration only in $2 \%$ and variable deceleration in $8 \%$ (Table 8 ). Meconium stained liquor was more common in tight nuchal cord group (17.3\%) than loose nuchal cord group (3\%).

\section{Neonatal outcome}

In this study when 300 deliveries with nuchal cord were observed, NICU admissions were required in $5.6 \%$ of newborns and $94.6 \%$ (283) of newborns were on mother's bedside (Table 9). ${ }^{17}$ Majority of NICU admitted newborns had tight NC. Apgar score of $<7$ at 1 minute was seen in $20.3 \%$ of newborns, Apgar score of $<7$ at 5 minutes was seen in only $1.3 \%$ (Table 10). The most dreaded complication of nuchal cord like birth asphyxia was seen only in $1 \%$. Thus effect of nuchal cord on fetus is suggested to be only transient without long term effect. Meconium stained liquor was seen in $9 \%$ of deliveries but only $2.3 \%$ of newborns suffered from meconium aspiration syndrome (Table 11). Meconium stained liquor was more common in tight nuchal cord group about 24 cases as compared to 5 cases in loose nuchal cord group. The neonatal mortality in this study was zero. Similarly, all these recent studies of Kasturi D et al, Mahendra G et al, Vasa R et al, Shrestha et al have showed no increase in adverse neonatal outcomes..$^{8,12,19,20}$ The neonatal complications which were observed were not serious but were treatable and mostly occurred with tight nuchal cord but were not statistically significant.

\section{CONCLUSION}

With routine use of ultrasound and doppler antenatally, nuchal cord is reported more commonly. Dread about nuchal cord is because of neonatal complications like birth asphyxia, stillbirth, cerebral palsy and increased operative delivery risk to mother. With many studies it is increasingly documented that women with nuchal cord can be safely allowed for vaginal delivery without increased maternal or neonatal complications.

Every pregnancy is precious and process of labour is dynamic and fetal distress can occur due to many reasons apart from nuchal cord, thus careful monitoring during labour and following labour room protocols will help detect complications and treat promptly to prevent any permanent damage. Only in anticipation of problems due to nuchal cord we are not justified in doing operative deliveries. So, we included in this study, pregnant women with sonographically detected nuchal cord, this should be way forward, that is from dread of complications due to nuchal cord to confident management with zero neonatal mortality.
Funding: No funding sources

Conflict of interest: None declared

Ethical approval: Not required

\section{REFERENCES}

1. Crawford S. Cord round the neck. Incidence and squeal. Acta Pediátrica. 1962;51:594-603.

2. Hankins GD, Snyder RR, Hauth JC, Gilstrap III LC, Hammond T. Nuchal cords and neonatal outcome. Obstet Gynecol. 1987;70:687e91.

3. Jauniaux E, Ramsay B, Peellaerts C, Scholler Y. Perinatal features of pregnancies complicated by nuchal cord. Am J Perinatol. 1995;12:255e8.

4. Larson J, Rayburn WF, Crosby S, Thurnau GR. Multiple nuchal cord entanglements and intrapartum complications. Am J Obstet Gynecol. 1995; 173:1228e31.

5. Onderoglu LS, Dursun P, Durukan T. Perinatal features and umbilical cord blood gases in newborns complicated with nuchal cord. Turk J Pediatr. 2008;50:466e70.

6. Zahoor F, Minhas Z, Zaki A. Perinatal outcome of nuchal cord. J Postgrad Med Inst. 2013;27:174e8.

7. Narang Y, Vaid NB, Jain S, Suneja K, Faridi MMA, Gupta B. Is nuchal cord justified as a cause of obstetrician anxiety? Arch Gynecol Obstet. 2014;289(4):795-801.

8. Mahendra P, Vidya LS, Pukale R, Bharathi. Clinical study of fetomaternal outcome in neonates with cord around neck in a tertiary care hospital. Sch J App Med Sci. 2015;3(1C):175-7.

9. Larson JD, Rayburn WF, Harlan VL. Nuchal cord entanglement and gestational age. Amer J Perinatol. 1997;14:555-7.

10. Mastrobattista JM, Hollier LM, Yeomons ER, Ramin SM, Day MC, Sosa, et al. Effects of nuchal cord on birthweight and immediate neonatal outcomes. Amer J Perinatol. 2005;22:83-5.

11. Schaffer, T. Burkhardt T, Zimmermann R, Kurmanavicius J. Nuchal cords in term and post term deliveries-Do we need to know? Obstet Gynecol. 2005;106:23-8.

12. Shresta NS, Singh N. Nuchal cord and perinatal outcome. Kathmandu Univ Med J. 2007;5:360-3.

13. Shui KP, Eastman NJ. Coiling of the umbilical cord around the fetal neck. J Obstet Gynaecol Br Emp. 1957;64:227-4.

14. Chatterjee AK, Gupta SS. Cord around the neck a study on 101 cases. J Obstet Gynecol India. 1985;5:660-4.

15. Joshi K, Saxena R, Bhat M, Lomrod Y, Verma K. Incidence of cord around the neck and its effects on labour and neonatal outcome. Adv Hum Biol. 2017;7:15-8.

16. Karunanidhi S, Ghose S, Pallavee P, Begum J, Rathod S. Maternal and neonatal outcome in newborns with nuchal cord loop: a comparative study. Int J Reprod Contracept Obstet Gynecol. 2015;4:1122-7. 
17. Peregrine E, O'Brien P, Jauniaux E. Ultrasound detection of nuchal cord prior to labour induction and the risk of caesarean 363 section. Ultrasound Obstet Gynecol. 2005;25(2):160-4.

18. Miser WF. Outcome of infants born with nuchal cords. Family practice service, Reynolds Army Community Hospital. Fortsill, UK. J Fam Pract. 1992;34(4):441-5.

19. Kasturi D, Marathe S, Manjunath N. A case control study on perinatal outcome in neonates with cord around the neck in a tertiary care hospital, Hubli, Karnataka. Int J Reprod Contracept Obstet Gynecol. 2014;3(1):105-8.
20. Vasa R, Dimitrov R, Patel S. Nuchal cord at delivery and perinatal outcomes: single-center retrospective study, with emphasis on fetal acid-base balance. Pediatr Neonatol. 2018;59(5):439-47.

Cite this article as: Shilpa SK, Moin S, Fatima N. Nuchal cord: from dread towards confident management. Int J Reprod Contracept Obstet Gynecol 2020;9:1820-4. 